\title{
Thin Smear Technique
}

National Cancer Institute

\section{Source}

National Cancer Institute. Thin Smear Technique. NCI Thesaurus. Code C85820.

A blood smear technique used to make a thin blood smear on a microscope slide which is generally used to look for blood parasites such as those causing malaria. 